\title{
The use of Ketamine-Xylazine and Ketamine-Medetomidine with and without their antagonists Yohimbine and Atipamezole Hydrochloride to immobilize Raccoons (Procyon lotor) in Ontario, Canada
}

\author{
Mike R. Allan
}

Ontario Ministry of Natural Resources and Forestry, Wildlife Research and Monitoring Section, Trent University, DNA Building, 2140 East Bank Drive, Peterborough, Ontario K9J 7B8 Canada; email: mike.allan@ontario.ca

Allan, Mike R. 2015. The use of ketamine-xylazine and ketamine-medetomidine with and without their antagonists, yohimbine and atipamezole hydrochloride to immobilize Raccoons (Procyon lotor) in Ontario, Canada. Canadian Field-Naturalist 129(1): 84-89.

This study was undertaken to identify a drug combination that provided a suitable plane of anesthesia and pain suppression and reduced recovery time for minor surgical procedures in raccoons. In fall 2004, 40 wild Raccoons (Procyon lotor) were chemically immobilized using ketamine hydrochloride combined with either xylazine or medetomidine hydrochloride. Immobilizing treatments within and between drug types were compared in terms of induction, arousal and recovery times. The ketamine-xylazine (KX) group $(n=20)$ was given a combination of $20 \mathrm{mg} / \mathrm{kg}$ ketamine hydrochloride and $2 \mathrm{mg} / \mathrm{kg}$ xylazine hydrochloride by body weight, and the effects on induction, arousal and recovery time were recorded with and without the antagonist yohimbine hydrochloride. The ketamine-medetomidine $(\mathrm{KM})$ group $(n=20)$ was given a combination of $5 \mathrm{mg} / \mathrm{kg}$ ketamine hydrochloride and $0.05 \mathrm{mg} / \mathrm{kg}$ medetomidine hydrochloride by body weight, and induction, arousal and recovery times were recorded with and without the use of the antagonist atipamezole hydrochloride. Administration of yohimbine hydrochloride at $0.1 \mathrm{mg} / \mathrm{kg}$ body weight to the $\mathrm{KX}$ group and atipamezole hydrochloride at $0.25 \mathrm{mg} / \mathrm{kg}$ body weight to the KM group produced considerably shorter arousal and recovery times in the $\mathrm{KM}$ group $(P=0.016)$. Mean arousal and recovery time with standard deviations \pm ( SD ) for the KX group with yohimbine hydrochloride antagonist were $36.10 \pm 10.69$ and $94.2 \pm 23.18$ minutes; for the KM group with atipamezole hydrochloride antagonist, they were $7.95 \pm 3.94$ and $65.58 \pm 14.75$ respectively. At these doses, the KM combination reversed with atipamezole hydrochloride significantly reduced arousal and recovery times and resulted in a quality of anesthesia that would allow safe tooth and blood extraction in Raccoons.

Key Words: ketamine; medetomidine; xylazine; yohimbine; atipamezole; raccoon; Procyon lotor; chemical immobilization

\section{Introduction}

Field immobilization of wildlife using various chemical immobilizing agents has been well documented (Mech et al. 1965; Bigler and Hoff 1974; Gregg and Olson 1975; Deresienski and Rupprecht 1989; Belant 1991, 2005; Kreeger 1999; Gehrt et al. 2001). The Ministry of Natural Resources and Forestry (MNRF) wildlife research and monitoring section has an ongoing research and management program in response to rabies in multiple terrestrial carnivore species (Rosatte et al. 1993, 2009). This has led to the development of many research projects involving the chemical immobilization of Red Foxes (Vulpes vulpes), Striped Skunks (Mephitis mephitis) and Raccoons (Procyon lotor) using various tranquilizers, sedatives and dissociative anesthetic agents (Rosatte and Allan 2009; Rosatte et al. 2010). Immobilizing agents are necessary to allow safe handling of live-trapped animals to acquire morphological measurements, permit ear-tagging, apply a radio collar or perform minor surgical procedures such as premolar tooth extraction and blood collection. Tooth and blood collection are required to determine bait acceptance and rabies antibody level following oral rabies vaccine delivery to foxes, skunks and raccoons by hand or aircraft (Rosatte et al. 1993, 2010, 2011). Surgical procedures such as tooth and blood extraction require an adequate level of anesthesia, muscle relaxation and pain suppression. Ketamine alone will provide anesthesia, however muscle relaxation is dosage dependent and pain suppression requires the addition of an analgesic (Gregg and Olson 1975; Fuller and Kuehn 1983; Dzialak et al. 2002). Although the analgesic promotes good muscle relaxation and pain suppression it may prolong recovery time (Dzialak et al. 2002). Combining ketamine with a tranquilizer or sedative has been observed to offset the convulsions often observed when using this drug and provide better muscle relaxation and analgesic properties in some wildlife species (Ramsden et al. 1976; Fuller and Kuehn 1983; Seal and Kreeger 1987; Dzialak et al. 2002; Rosatte and Allan 2009). Not all tranquilizers are reversible but recovery time can be reduced by reversing sedatives using alpha- 2 antagonists. Improvements in recovery time have been observed after administering yohimbine hydrochloride to reverse the effects of xylazine in Mule Deer (Odocoileus hemionus), White-tailed Deer (Odocoileus virginianus), Elk (Cervus elaphus), Polar Bears (Ursus maritimus) and Raccoons (Jessup et al. 1983; Mech et al. 1985; Ramsay et al. 1985; Deresienski and Rupprecht 1989; Rosatte 2007). Ideally, field operations require the safe release of animals following immediate recovery from anesthetic, hence, the need for a drug combination that immobilizes animals safely and reduces recovery time.

Medetomidine hydrochloride is an alpha-2 agonist that is more potent and 10 times more selective than xylazine hydrochloride; it actively attaches to sites at a ratio of 1620:1 compared with 160:1 for xylazine (Sin- 
clair 2003). Medetomidine hydrochloride has been administered to Coyotes (Canis latrans), Red Foxes and Raccoons with reasonable success in animal handling procedures such as measurements and innoculations (Baldwin et al. 2008). When combined with ketamine hydrochloride, medetomidine hydrochloride has been used effectively to chemically restrain a variety of other wildlife species (Tsuruga et al. 1999; Haulena and Gulland 2001; Fernandez-Moran et al. 2001; Dzialak et al. 2002; Bieglböck and Zenker 2003; Fournier-Chambrillon et al. 2003; Belant 2005; Robert et al. 2012). The effects of this combination can be quickly reversed using the antagonist atipamezole hydrochloride and this procedure has demonstrated smooth induction, good immobilization and rapid recovery in Eurasian Otters, (Lutra lutra) European Mink (Mustela lutreola), Polecat (Mustela putorius) (Fernandez-Moran et al. 2001; Fournier-Chambrillon et al. 2003) and Raccoons (Robert et al. 2012). The ketamine-medetomidine combination has been reported to provide a good level of anesthesia and muscle relaxation and a better quality of surgical anesthesia than a ketamine-xylaxine combination in rabbits (Henke et al. 2005).

The purpose of this study was to compare KX and $\mathrm{KM}$ drug combinations with and without antagonists and their effects on induction, arousal and recovery times. I also evaluated which drug combination meets the pain suppression and muscle relaxation requirements during minor surgical procedures and demonstrates the shortest recovery time in Raccoons.

\section{Methods}

During the week of 6-10 September, as part of MNRF rabies research operations in the Niagara region $\left(43^{\circ} 05^{\prime} \mathrm{N}, 79^{\circ} 05^{\prime} \mathrm{W}\right)$, Raccoons were randomly trapped using number 108 and 106 Tomahawk live traps (Tomahawk Live Trap Company, Hazelhurst, Wisconsin, USA), baited with sardines in soya oil. Animals were transported by pick-up truck and housed at the Codrington Research Facility, Codrington, Ontario, Canada $\left(44^{\circ} 08^{\prime} \mathrm{N}, 77^{\circ} 48^{\prime} \mathrm{W}\right)$. Animals were divided into two groups of 20 animals that were similar in terms of age and sex. The KX group included four adult males, five adult females, six juvenile males and five juvenile females. The KM group included five adult males, five adult females, four juvenile males and six juvenile females. Each animal was transferred from the trap into a plywood nesting box $(60 \mathrm{~cm} \times 58 \mathrm{~cm} \times 30 \mathrm{~cm})$ with access to an individual wire cage holding pen $(152 \mathrm{~cm}$ $\times 60 \mathrm{~cm} \times 60 \mathrm{~cm})$ and allowed to acclimatize for 1 week before treatment. Raccoons were fed 170 grams per day of fox maintenance feed, (Martin Mills Inc., and Elmira Ontario, Canada) and provided with water on a daily basis. Animals were not fed on the morning of the experiment and feeding was postponed until all animals had recovered fully from the anesthetic. Raccoons were captured in their nesting boxes using a 4-foot snare pole (Ketch-all San Luis Obispo, California USA) and placed into a Tomahawk 108 live trap and weighed to the nearest tenth of a kilogram minus the trap weight. Mean ambient air temperature was calculated using hourly data from Environment Canada from 1000 to 1600 EST (Environment Canada 2014) which included the time frame of the treatments.

Treatment one commenced on 20 September 2004. The KX group was immobilized using a 10:1 ratio of the two drugs by body weight: $20 \mathrm{mg} / \mathrm{kg}$ ketamine hydrochloride (Rogarsetic $50 \mathrm{~mL}, 100 \mathrm{mg} / \mathrm{mL}$, Pfizer Canada Inc., Pointe-Claire, Quebec, Canada) and $2 \mathrm{mg} /$ $\mathrm{kg}$ of xylazine hydrochloride (Anased $50 \mathrm{~mL}, 100 \mathrm{mg} /$ $\mathrm{mL}$, Novopharm Ltd., Toronto, Ontario, Canada). Raccoons were restrained in their nesting boxes using a plunger squeeze technique and given an intramuscular injection into the quadriceps muscle of the hind limb using a handheld $3 \mathrm{~mL}$ syringe with 22 gauge needle. Mean ambient air temperature was $19.8^{\circ} \mathrm{C}$.

On 21 September 2004, the KM group was immobilized 100:1 ratio of the two drugs by body weight; $0.05 \mathrm{mg} / \mathrm{kg}$ ketamine hydrochloride and $0.050 \mathrm{mg} / \mathrm{kg}$ medetomidine hydrochloride (Domitor, $10 \mathrm{~mL}, 1.0 \mathrm{mg}$ / $\mathrm{mL}$, Novartis Animal Health Canada Inc. Mississauga, Ontario, Canada). Mean ambient air temperature was $23.9^{\circ} \mathrm{C}$.

Treatment two began on 5 October 2004 with the $\mathrm{KX}$ group receiving the same drug combination as in the first treatment. Approximately 18 minutes postinduction the animals received the antagonist yohimbine hydrochloride (Lloyd Yobine, $20 \mathrm{~mL}, 2 \mathrm{mg} / \mathrm{mL}$ (Teva Canada, Scarborough, Ontario, Canada) at a dosage of $0.1 \mathrm{mg} / \mathrm{kg}$. Mean ambient air temperature was $10.1^{\circ} \mathrm{C}$

On 6 October 2004, the KM group was immobilized using the same dose as in the first treatment followed by intramuscular injection of the antagonist atipamezole hydrochloride (Antisedan, $10 \mathrm{~mL}, 5.0 \mathrm{mg} / \mathrm{mL}$, Novartis Animal Health Inc.) at a dose of $0.25 \mathrm{mg} / \mathrm{kg} 18 \mathrm{~min}$ utes post-induction. Mean ambient temperature was $16.4^{\circ} \mathrm{C}$.

Injection, induction, arousal and recovery times were recorded for individual animals in each group. Injection time was recorded as the time following injection: induction time was measured as the time following injection to lack of responsiveness to tactile stimuli (palpebral reflex and toe pinch). Arousal time was recorded as time from induction to the animal's first attempt to raise its head from the floor of the holding pen. Recovery time was recorded as the time from arousal to lack of ataxia in the hind limbs. Antagonists were injected on average 18 minutes after induction to simulate the length of a minor surgical procedure. All animals were handled according to MNRF Animal Care Committee protocol \#04-91.

\section{Data analysis}

Induction, arousal and recovery times were entered into Excel (windows version 2000, Microsoft, Red- 
mond, Washington, USA) and exported into Statistica ${ }^{\circledR}$ version 6.0 (Statsoft, Tulsa, Oklahoma, USA). Before analysis, $\log$ transformation of all data was completed to establish normality and achieve homogeneity of variances. Data for one animal from the KM group were excluded during analysis as normality could not be attained because of an overly long recovery time. Differences in induction, arousal and recovery times were tested within and between drug combinations for the two treatments. A MANOVA was used to detect differences within and between the KX and KM groups. Differences between age and sex classes were not examined as sample sizes were considered too small, i.e., low power increased the chance for Type II error (Zar 1999). Mean value statistics, standard deviation and range for each group were calculated. Alpha was set at $P=0.05$.

\section{Results}

Analysis of covariance showed that body weight had no significant effect on induction, arousal or recovery time $(P>0.05)$.

During treatment one, when no antagonist was used and comparisons between induction, arousal and recovery times were made between the KX and KM drug types, shorter induction, arousal and recovery times were observed for the $\mathrm{KX}$ drug combination $\left(F_{(2,76)}\right.$ $=7.31, P=0.001$ ).

In treatment two, when antagonists were used, induction time for the $\mathrm{KX}$ group was twice as long as in treatment one $(P=0.026)$. Arousal and recovery times were significantly shorter following administration of yohimbine hydrochloride $(P<0.001$ and $P=$ $0.015)$ respectively and significant differences were found for induction, arousal and recovery times when comparing treatments within the $\mathrm{KX}$ group $\left(F_{(2,76)}=\right.$ $10.74, P<0.001)$. For the KM group, when the antagonist atipamezole hydrochloride was used, shorter arousal and recovery times were observed compared with treatment one $(P<0.001)$ with no differences observed between induction times, and significant differences were observed between treatments for induction, arousal and recovery times $\left(F_{(2,74)}=22.72, P<\right.$ $0.001)$.

Comparing drug combinations, no significant differences were observed regarding induction time. Rac- coons in the KM group demonstrated significantly shorter arousal and recovery times when given atipamezole hydrochloride compared with those in the KX group given yohimbine hydrochloride $\left(F_{(2,74)}=4.354\right.$, $P=0.016)$. Differences in induction, arousal and recovery times within and between drug combinations are shown in Table 1.

\section{Discussion}

Variation in the length of induction time to induce anesthesia in raccoons was observed in the KX group between treatments. Poor induction may be attributed to the behavior of individual animals before immobilization and may be attributable to various biological or behavioural influences. Some animals were very calm during injection while others displayed aggression. Animals were restrained in nesting boxes by quickly lifting the lid and pinning the Raccoon using a plunger type squeeze technique. Although Raccoons were often restrained quickly, more aggressive animals took longer to restrain. Prolonged restraint coupled with the aggressive and agitated state of these animals may be the reason for some of the variation observed in induction times between the two treatments in the KX group. Aggressive behavior has been known to affect drug absorption and result in failure to achieve optimum sedation (Sinclair 2003). Because I did not record animal behavior for every injection I cannot say whether aggressive behavior affected induction time in the KX group.

Repeated exposure to drugs is thought to prolong induction and recovery times in some mammals. This has been observed in seals and raccoons, where repeated exposure to ketamine and medetomidine increased induction time (Field et al. 2002; Wheatley et al. 2006; Robert et al. 2012). In this study, an increase in induction during the second $\mathrm{KX}$ treatment was observed; however, no significant difference in induction time was observed in the KM group. Although the increased induction time in the KX group might be a result of drug tolerance, it could also be related to other biological or ambient conditions.

A study in Quebec observed longer induction time for Raccoons administered KM in the fall, indicating lower ambient temperature and increased body fat may affect drug absorption at this time of year (Baldwin $e t$

TABLE 1. Induction, arousal and recovery times of Raccoons (Procyon lotor) administered ketamine hydrochloride combined with either xylazine hydrochloride or medetomidine hydrochloride without and with the antagonists yohimbine hydrochloride and atipamezole hydrochloride respectively.

\begin{tabular}{lcccc}
\hline \hline $\begin{array}{l}\text { Drug } \\
\text { combination }\end{array}$ & $n$ & $\begin{array}{c}\text { Induction time } \\
\text { mean } \pm \mathrm{SD}(\text { range) }\end{array}$ & $\begin{array}{c}\text { Arousal time } \\
\text { mean } \pm \text { SD (range) }\end{array}$ & $\begin{array}{c}\text { Recovery time } \\
\text { mean } \pm \text { SD (range) }\end{array}$ \\
\hline KX without YH & 20 & $3.6 \pm 2.54(1-10)$ & $55 \pm 16.06(28-95)$ & $113.65 \pm 26.41(73-160)$ \\
KX with YH & 20 & $6.25 \pm 4.84(2-19)$ & $36.10 \pm 10.69(18-60)$ & $94.2 \pm 23.18(61-145)$ \\
KM without AH & 19 & $6.74 \pm 3.81(2-18)$ & $71.73 \pm 24.23(43-147)$ & $132.1 \pm 37.24(75-201)$ \\
KM with AH & 19 & $7.63 \pm 4.68(2-17)$ & $7.95 \pm 3.94(3-15)$ & $65.58 \pm 14.75(37-99)$ \\
\hline \hline
\end{tabular}

Note: $\mathrm{AH}=$ atipamezole hydrochloride, $\mathrm{SD}=$ standard deviation, $\mathrm{YH}=$ yohimbine hydrochloride. 
al. 2008; Robert et al. 2012). In my study, the mean ambient temperature was almost $10^{\circ} \mathrm{C}$ cooler during the second treatment which might explain the much longer induction time observed in the KX group. Mean ambient temperature differences for the KM group was $7.5^{\circ} \mathrm{C}$ and no differences in induction time were observed between treatments in that group suggesting that there may be a temperature threshold that delays induction however this was beyond the scope of this study.

Larger body mass has been known to cause slower induction and recovery times in the North American Porcupine (Erethizon dorsatum) (Morin and Berteaux, 2003); however, based on the analysis of covariance in this study, weight had no impact on induction, arousal or recovery times in Raccoons. The restraining technique used in this study provided clear access to the quadriceps muscle allowing a good site for intramuscular injection. Therefore differences in induction time are not likely attributable to faulty injection. Thus reasons for the differences in induction between treatments in the $\mathrm{KX}$ group remain unclear.

In the absence of an antagonist, $\mathrm{KX}$ allows shorter induction, arousal and recovery times than KM in Raccoons. This has also been observed in Alpine Marmots (Marmota marmota) where induction times were not significantly different, but arousal and recovery times were significantly longer in the KM group (Bieglböck and Zenker 2003).

For the KX group in this study, shorter arousal and recovery times were expected following intramuscular injection of the antagonist yohimbine hydrochloride. Xylazine attaches to the presynaptic adrenoreceptors, reducing the release of norepinephrine. Yohimbine reverses the xylaxine hydrochloride at the presynaptic adrenoreceptors, thus increasing the release of norepinephrine (Langer 1980; Kreeger et al. 1987). Reversing the effects of xylazine hydrochloride with yohimbine via intramuscular, sublingual or intravenous administration has been observed to reduce recovery times in a number of mammalian species (Jessup et al. 1983; Mech et al. 1985; Ramsay et al. 1985; Kreeger et al. 1987; Deresienski and Rupprecht 1989; Rosatte 2007). Although sublingual, femoral or jugular intravenous injection may be feasible in larger mammals, it is less desirable in operations involving large numbers of meso-carnivores where veins are smaller and where intramuscular injection is more practical (Rosatte et al. 2009).

Medetomidine hydrochloride induces sedation for up to 70-90 minutes when administered intramuscularly at doses of $0.03 \mathrm{mg} / \mathrm{kg}$ by weight in dogs and cats. Higher doses $>0.080 \mathrm{mg} / \mathrm{kg}$ will not increase sedation, but will prolong recovery (Sinclair 2003). In my study, drug dosages of $0.05 \mathrm{mg} / \mathrm{kg}$ medetomidine hydrochloride and $5 \mathrm{mg} / \mathrm{kg}$ ketamine hydrochloride were used on Raccoons and sedation periods averaged 124.36 minutes without administration of the antago- nist atipamezole hydrochloride. Longer recovery times averaging 199.4 minutes were observed in the Fisher (Martes pennanti) using slightly higher doses of medetomidine hydrochloride $(0.07 \mathrm{mg} / \mathrm{kg})$ and lower ketamine hydrochloride doses averaging $3.7 \mathrm{mg} / \mathrm{kg}$ for males and $3.6 \mathrm{mg} / \mathrm{kg}$ for females (Dzialak et al. 2002). In the absence of an antagonist, perhaps a lower dose of medetomidine hydrochloride could be considered for non-surgical operations to reduce recovery periods in Raccoons and Fishers.

Reversing the KM drug combination using atipamezole hydrochloride resulted in shorter arousal and recovery times for Raccoons in this study. Similar results have been observed in Polar Bears, Sika (Cervus Nippon), Eurasian Otter, European Mink, European Polecat and Raccoons (Cattet et al. 1997; Tsuruga et al. 1999; Fernandez-Moran et al. 2001; Fournier-Chambrillon et al. 2003; Robert et al. 2012). This was expected as atipamezole hydrochloride fully antagonizes the sedative and behavioural effects of medetomidine hydrochloride when administered at four to six times the medetomidine hydrochloride dose (Sinclair 2003). In this experiment, medetomidine hydrochloride antagonized at five times the atipamezole hydrochloride dosage $(0.25 \mathrm{mg} / \mathrm{kg})$ and Raccoons were walking shortly after arousal but demonstrated limb ataxia likely attributable to the residual ketamine. Ketamine hydrochloride has no known antagonist. Although administering yohimbine hydrochloride has been reported to shorten arousal times in the Gray Wolf (Canis lupus) and Domestic cat (Felis catus), no improvement was observed in walking times (Hatch et al. 1983; Kreeger and Seal 1986a; Kreeger and Seal 1987). The shorter arousal times observed in the KM group may be attributed to the lower dose of ketamine $(5 \mathrm{mg} / \mathrm{kg}$ compared with $20 \mathrm{mg} / \mathrm{kg}$ in the KX group) and the intramuscular administration of atipamezole hydrochloride. Given that yohimbine hydrochloride shortens arousal time in wolves and cats, and atipamezole hydrochloride is also an alpha-2 antagonist, it is likely that the atipamezole hydrochloride is stimulating the nervous system of Raccoons in a similar manner and contributing to shorter arousal times in the KM group.

The KM drug combination requires significantly less ketamine hydrochloride than the KX drug combination for the chemical immobilization of Raccoons. Given that ketamine is a restricted drug in Canada, lower volumes are more likely to be approved and are easier to track and maintain by the biologist. KM has been used successfully in live-animal capture programs in MNRF rabies control programs. In large-scale field operations, we successfully immobilized and performed minor surgical procedures on over 1200 Raccoons and Striped Skunks using $550 \mathrm{~mL}$ of ketamine, averaging less than $0.5 \mathrm{~mL}$ of ketamine per animal (Rosatte et al. 2009). For the same number of animals, we would have used four times the volume of ketamine if it was 
combined with xylazine hydrochloride, a difference of $\$ 1300$ in cost of ketamine alone.

$\mathrm{KM}$ and the antagonist atipamezole hydrochloride is a better drug combination for reducing recovery in Raccoons compared with KX antagonized with yohimbine hydrochloride. No mortalities or adverse reactions were observed indicating that the drugs are safe at these doses. Smooth induction, good muscle relaxation, rapid arousal and recovery combined with a wide safety margin make $\mathrm{KM}$ a good replacement for $\mathrm{KX}$ for performing tooth and blood extraction procedures on Raccoons.

\section{Acknowledgements}

This project was funded by the Ontario Ministry of Natural Resources and Forestry Rabies Research and Development Program and approved by Dr. J. Chris Davies, Manager of Wildlife Research and Monitoring Section. I thank Dr. Graham Crawshaw and his associate Dr. Mats Bertelson for sharing their knowledge and training in the areas of chemical immobilization of mammals and their recommendations for conducting a trial on raccoons. I also thank Scott Taylor and Vaughan Jamieson for their animal husbandry expertise and assistance during the experiment; Scott Norton and the Niagara trapping staff of the Rabies Research and Development Unit for their assistance in capturing and delivering the animals for the trial; Linh Nguyen, parttime professor at Trent University for his advice, knowledge, patience and time in helping me with the statistical analyses; Dr. Dennis Murray of Trent University, Dr. Rick Rosatte and Beverly Stevenson of Ministry of Natural Resources and Forestry for providing comments and suggestions and reviewing the manuscript; and associate editors and reviewers of the Canadian Field Naturalist for their useful comments and suggestions for improving this manuscript.

\section{Literature Cited}

Baldwin, J. R., J. B. Winstead, L. D. Hayden-Wing, T. J. Kreeger, and M. R. Dzialak. 2008. Field sedation of coyotes, red foxes, and raccoons with medetomidine and atipamezole. Journal of Wildlife Management 72(5): 12671271.

Bieglböck, C., and W. Zenker. 2003. Evaluation of three combinations of anesthetics for use in free-ranging alpine marmots (Marmota marmota). Journal of Wildlife Diseases 39(3): 665-674.

Belant, J. L. 1991. Immobilization of fishers (Martes pennanti) with ketamine hydrochloride and xylazine hydrochloride. Journal of Wildlife Diseases 27(2): 328-330.

Belant, J. L. 2005. Tiletamine-zolazepam-xylazine immobilization of American marten (Martes americana). Journal of Wildlife Diseases 41(3): 659-663.

Bigler, W. J., and G. L. Hoff. 1974. Anesthesia of raccoons with ketamine hydrochloride. Journal of Wildlife Management 38(2): 364-366.

Cattet, M., A. Nigel, S. Caulkett, C. Polischuk, and M. A. Ramsay. 1997. Reversible immobilization of free-ranging polar bears with medetomidine-zolazepam-tiletamine and atipamezole. Journal of Wildlife Diseases 33(3): 611-617.
Dematteis, A., A. Menzano, G. Canavese, P. G. Meneguz, and L. Rossi. 2009. Anaesthesia of free-ranging Northern chamois (Rupicapra rupicapra) with xylazine/ketamine and reversal with atipamezole. European Journal of Wildlife Research 55(6): 567-573.

Deresienski, D. T., and C. E. Rupprecht. 1989. Yohimbine reversal of ketamine-xylazine immobilization of raccoons (Procyon lotor). Journal of Wildlife Diseases 25(2): 169174.

Dzialak, M. R., T. L. Serfass, D. L. Shumway, L. M. Hegde, and T. L. Blankenship. 2002. Chemical restraint of fishers (Martes pennanti) with ketamine and medetomidineketamine. Journal of Zoo and Wildlife Medicine 33(1): 45-51.

Dzialak, M.R., L. Thomas, L. Serfass, and T. L. Blankenship. 2007. Reversible chemical restraint of fishers with medetomidine-ketamine and atipamezole. Journal of Wildlife Management 65(1): 157-163.

Environment Canada. 2014. Climate. Environment Canada, Ottawa, Ontario, Canada, Accessed 19 June, 2014. http: //climate.weather.gc.ca/index_e.html.

Fernandez-Moran, J., E. Perez, M. Sanmartin, D. Saavedra, and X. Manteca-Vilanova. 2001. Reversible immobilization of Eurasian otters with a combination of ketamine and medetomidine. Journal of Wildlife Diseases 37(3): 561-565.

Field, I. C., C. J. Bradshaw, C. R. McMahon, J. Harrington, and H. R. Burton. 2002. Effects of age, size and condition of elephant seals (Mirounga leonina) on their intravenous anaesthesia with tiletamine and zolazepam. Veterinary Record 151(8): 235-240.

Fournier-Chambrillon, C., J. P. Chusseau, J. Dupuch, C. Maizeret, and P. Fournier. 2003. Immobilization of free-ranging European mink (Mustela lutreola) and Polecat (Mustela putorius) with medetomidine-ketamine and reversal by atipamezole. Journal of Wildlife Diseases 39(2): 393-399.

Fuller, T. K., and D. W. Kuehn. 1983. Immobilization of wolves using ketamine in combination with xylazine or promazine. Journal of Wildlife Diseases 19(1): 69-72.

Gehrt, S. D., L. L. Hungerford, and S. Hatten. 2001. Drug effects on recaptures of raccoons. Wildlife Society Bulletin 29(3): 833-837.

Gregg, D. A., and L. D. Olson. 1975. The use of ketamine hydrochloride as an anesthetic for raccoons. Journal of Wildlife Diseases, 11(3): 335-337.

Hatch, R. C., N. H. Booth, J. V. Kitzman, B. M. Wallner, and J. D. Clark. 1983. Antagonism of ketamine anesthesia in cats by 4-aminopyridine and yohimbine. American Journal of Veterinary Research 44(3): 417-23.

Haulena, M., and F. M. Gulland. 2001. Use of medetomidinezolazepam-tiletamine with and without atipamezole reversal to immobilize captive California sea lions. Journal of Wildlife Diseases 37(3): 566-573.

Henke, J., S. Astner, T. Brill, B. Eissner, R. Busch, and W. Erhardt. 2005. Comparative study of three intramuscular anesthetic combinations (medetomidine/ketamine, medetomidine/fentanyl/midazolam and xylazine/ketamine) in rabbits. Veterinary Anesthesia and Analgesia 32(5): 261270.

Jessup, D. A., W. E. Clark, P. A. Gullett, and K. R. Jones. 1983. Immobilization of mule deer with ketamine and xylazine, and reversal of immobilization with yohimbine. Journal of the American Veterinary Medical Association 183(11): 1339-1340. 
Jorgenson, J. T., J. Samson, and M. Festa-Bianchet. 1990 Field immobilization of bighorn sheep with xylazine hydrochloride and antagonism with idazoxan. Journal of Wildlife Diseases 26(4): 522-527.

Kreeger, T. J., A. M. Faggella, U. S. Seal, L. D. Mech, M. Callahan, and B. Hall. 1987. Cardiovascular and behavioral responses of gray wolves to ketamine-xylazine immobilization and antagonism by yohimbine. Journal of Wildlife Diseases 23(3): 463-470.

Kreeger, T. J., and U.S. Seal. 1986a. Failure of yohimbine hydrochloride to antagonize ketamine hydrochloride immobilization of gray wolves. Journal of Wildlife Diseases 22(4): 600-603.

Langer, S. Z. 1980. Presynaptic regulation of the release of catecholamines. Pharmacological Reviews 32(4): 337-362.

Mech, L. D., G. D. Giudice, P. D. Karns, and U. S. Seal. 1985. Yohimbine hydrochloride as an antagonist to xylazine hydrochloride-ketamine hydrochloride immobilization of white-tailed deer. Journal of Wildlife Diseases 21(4): 405410.

Morin, P., and D. Berteaux. 2003. Immobilization of North American porcupines (Erethizon dorsatum) using ketamine and xylazine. Journal of Wildlife Diseases 39(3): 675-682.

Ramsay, M. A., I. Stirling, L. Knutson, and E. Broughton. 1985. Use of yohimbine hydrochloride to reverse immobilization of polar bears by ketamine hydrochloride and xylazine hydrochloride. Journal of Wildlife Diseases 21(4): 396-400.

Ramsden, R. O., P. F. Coppin, and D. H. Johnston. 1976. Clinical observations on the use of ketamine hydrochloride in wild carnivores. Journal of Wildlife Diseases 12(2): 221-225.

Robert, K., D. Garant, and F. Pelletier. 2012. Chemical immobilization of raccoons (Procyon lotor) with ketaminemedetomidine mixture and reversal with atipamezole. Journal of Wildlife Diseases 48(1): 122-130.

Rosatte, R. 2007. Immobilization of Elk, Cervus elaphus, with telazol and xylazine and reversal with tolazine or yohimbine. Canadian Field-Naturalist 121(1): 62-66.

Rosatte, R., and M. Allan. 2009. The ecology of Red Foxes, Vulpes vulpes, in metropolitan Toronto, Ontario: disease management implications. Canadian Field-Naturalist 123(3): 215-220.

Rosatte, R. C., D. Donovan, J. C. Davies, M. Allan, P. Bachmann, B. Stevenson, K. Sobey, L. Brown, A. Silver, K. Bennett, T. Buchanan, L. Bruce, M. Gibson, A. Beres- ford, A. Beath, C. Fehlner-Gardiner, and K. Lawson.

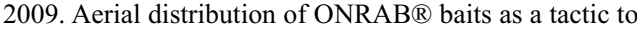
control rabies in raccoons and striped skunks in Ontario, Canada. Journal of Wildlife Diseases 45(2): 363-374.

Rosatte, R. C., C. D. MacInnes, M. J. Power, D. H. Johnston, P. Bachmann, C. P. Nunan, C. Wannop, M. Pedde, and L. Calder. 1993. Tactics for the control of wildlife rabies in Ontario (Canada). Revue scientifique et technique (International Office of Epizootics) 12(1): 95-98.

Rosatte, R. C., M. Ryckman, K. Ing, S. Proceviat, M. Allan, L. Bruce, D. Donovan, and J. C. Davies. 2010. Density, movements, and survival of raccoons in Ontario, Canada: implications for disease spread and management. Journal of Mammalogy 91(1): 122-135.

Rosatte, R. C., D. Donovan, J. C. Davies, L. Brown, M. Allan, V. von Zuben, P. Bachmann, K. Sobey, A. Silver, K. Bennett, T. Buchanan, L. Bruce, M. Gibson, M. Purvis, A. Beresford, A. Beath, and C. Fehlner-Gardiner.

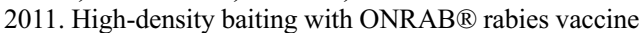
baits to control Arctic-variant rabies in striped skunks in Ontario, Canada. Journal of Wildlife Diseases 47(2): 459 465.

Seal, U. S., and T. J. Kreeger. 1987. Chemical immobilization of furbearers. Pages 191-215 in Wild Furbearer Management and Conservation in North America. Edited by M. Novak, J.A. Baker, M. E. Obbard and B. Malloch. Ministry of Natural Resources, Toronto, Ontario, Canada

Sinclair, M. D. 2003. A review of the physiological effects of alpha2-agonists related to the clinical use of medetomidine in small animal practice. Canadian Veterinarian Journal 44(11): 885-897.

Tsuruga, H., M. Suzuki, H. Takahashi, K. Jinma, and K. Kaji. 1999. Immobilization of sika deer with medetomidine and ketamine and antagonism by atipamezole. Journal of Wildlife Diseases 35(4): 774-778.

Wheatley, K. E., C. J. A. Bradshaw, R. G. Harcourt, L. S. Davies, and M. A. Hindell. 2006. Chemical immobilization of adult female Weddell seals with tiletamine and zolazepam: effects of age, condition and stage of lactation. BMC Veterinary Research 2(1): 8.

Zar, J. H. 1999. Biostatistical Analysis. Prentice Hall, Upper Saddle River, New Jersey, USA.

Received 29 July 2014

Accepted 7 November 2014 